Cochrane Database of Systematic Reviews

\title{
Zinc supplementation for the treatment of measles in children
} (Review)

Awotiwon AA, Oduwole O, Sinha A, Okwundu CI

Awotiwon AA, Oduwole O, Sinha A, Okwundu Cl.

Zinc supplementation for the treatment of measles in children.

Cochrane Database of Systematic Reviews 2017, Issue 6. Art. No.: CD011177.

DOI: 10.1002/14651858.CD011177.pub3.

www.cochranelibrary.com 
TABLE OF CONTENTS

HEADER 1

ABSTRACT

PLAIN LANGUAGE SUMMARY

SUMMARY OF FINDINGS

BACKGROUND

OBJECTIVES

METHODS

RESULTS

Figure 1.

Figure 2.

Figure 3.

Figure 4.

DISCUSSION

AUTHORS' CONCLUSIONS

ACKNOWLEDGEMENTS

REFERENCES

CHARACTERISTICS OF STUDIES

DATA AND ANALYSES

Analysis 1.1. Comparison 1 Zinc versus placebo, Outcome 1 Mortality.

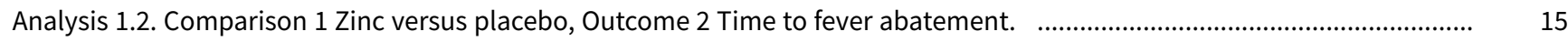
APPENDICES

WHAT'S NEW

CONTRIBUTIONS OF AUTHORS

DECLARATIONS OF INTEREST

SOURCES OF SUPPORT

INDEX TERMS 
[Intervention Review]

\title{
Zinc supplementation for the treatment of measles in children
}

\author{
Ajibola A Awotiwon ${ }^{1}$, Olabisi Oduwole ${ }^{2}$, Anju Sinha ${ }^{3}$, Charles I Okwundu 4
}

1Knowledge Translation Unit, University of Cape Town Lung Institute, Observatory, Cape Town, South Africa. 2 Institute of Tropical Diseases Research and Prevention, University of Calabar Teaching Hospital (ITDR/P), Calabar, Nigeria. ${ }^{3}$ Division of Child Health, Indian Council of Medical Research, Ansari Nagar, India. ${ }^{4}$ Centre for Evidence-based Health Care, Faculty of Medicine and Health Sciences, Stellenbosch University, Cape Town, South Africa

Contact address: Ajibola A Awotiwon, Knowledge Translation Unit, University of Cape Town Lung Institute, George street, Observatory, Cape Town, Western Cape, 7700, South Africa. docjibbs@yahoo.com.

Editorial group: Cochrane Acute Respiratory Infections Group.

Publication status and date: New search for studies and content updated (no change to conclusions), published in Issue 6, 2017.

Citation: Awotiwon AA, Oduwole O, Sinha A, Okwundu CI. Zinc supplementation for the treatment of measles in children. Cochrane Database of Systematic Reviews 2017, Issue 6. Art. No.: CD011177. DOI: 10.1002/14651858.CD011177.pub3.

Copyright @ 2017 The Cochrane Collaboration. Published by John Wiley \& Sons, Ltd.

\section{A B S T R A C T}

\section{Background}

Measles is an important cause of childhood morbidity and mortality globally, despite increasing vaccine coverage. Zinc plays a significant role in the maintenance of normal immunological functions, therefore supplements given to zinc-deficient children will increase the availability of zinc and could reduce measles-related morbidity and mortality. This is an update of a review first published in 2015.

\section{Objectives}

To assess the effects of zinc supplementation in reducing morbidity and mortality in children with measles.

\section{Search methods}

We searched CENTRAL (03 February 2017, Issue 2), MEDLINE (1946 to 03 February 2017), Embase (1974 to 03 February 2017), CINAHL (1981 to 03 February 2017), LILACS (1982 to 03 February 2017), Web of Science (1985 to 03 February 2017), and BIOSIS Previews (1985 to 27 June 2014). We also searched ClinicalTrials.gov, the Australian New Zealand Clinical Trials Registry and the World Health Organization (WHO) International Clinical Trials Registry Platform (ICTRP) on 03 February 2017 to identify unpublished and ongoing studies.

\section{Selection criteria}

Randomised controlled trials (RCTs) and quasi-RCTs evaluating the effects of zinc in reducing morbidity and mortality in children with measles.

\section{Data collection and analysis}

Two review authors independently assessed the studies for inclusion and extracted data on outcomes, details of the interventions, and other study characteristics using a standardised data extraction form. We used risk ratio (RR) and hazard ratio (HR) as measures of effect with $95 \%$ confidence intervals $(\mathrm{Cl})$. We included only one study, and did not conduct meta-analysis.

\section{Main results}

We did not identify any new studies for inclusion in this update. One RCT met our inclusion criteria. The study was conducted in India and included 85 children diagnosed with measles and pneumonia. The trial showed no significant difference in mortality between children with measles and pneumonia who received zinc supplements and those who received placebo (RR $0.34,95 \% \mathrm{Cl} 0.01$ to 8.14 ). There was no significant difference in time to absence of fever between children who received zinc supplements and those who did not (HR $1.08,95 \% \mathrm{Cl}$ 0.67 to 1.74). No treatment-related side effects were reported in either group. We assessed the overall quality of the evidence as very low. 


\section{Authors' conclusions}

We could not draw any definitive conclusions from this review about the effects of zinc supplementation on clinical outcomes of children with measles due to the very low quality of the evidence available. There is insufficient evidence to confirm or refute the effect of zinc supplementation in children with measles.

\section{PLAIN LANGUAGE SUMMARY}

\section{Zinc supplementation for the treatment of measles in children}

\section{Review question}

What is the effect of zinc supplementation in the treatment of children with measles?

\section{Background}

Measles infection has reduced globally over the last decade, but large outbreaks still occur, especially in low-income countries. Zinc is one of the essential micronutrients necessary for the optimal functioning of the immune system. Zinc deficiency is particularly common in children in low- and middle-income countries. It was therefore important to examine the potential role of zinc supplementation in controlling the symptoms of measles infection in children.

We aimed to critically assess the current evidence from published studies on the effect of zinc supplementation for the treatment of measles in children.

\section{Search date}

We searched for evidence up to 03 February 2017. This is an update of a review first published in 2015. We did not include any new studies for this update.

\section{Study characteristics}

We found one small randomised trial (involving 85 children) that compared zinc supplements versus placebo administered to children with measles and pneumonia. All 85 children received supportive care and vitamin A. The study was conducted in India and funded by the Child Health Foundation USA and the Nestlé Foundation.

\section{Key results}

The included study was small and did not provide enough data to determine whether zinc had an effect on mortality when compared with placebo. Although no adverse effects were reported, there was insufficient evidence to draw any conclusions about the use of zinc supplements to improve measles symptoms in children. More research is needed to clarify any benefits or harms.

\section{Quality of the evidence}

We assessed the quality of the evidence as very low. 


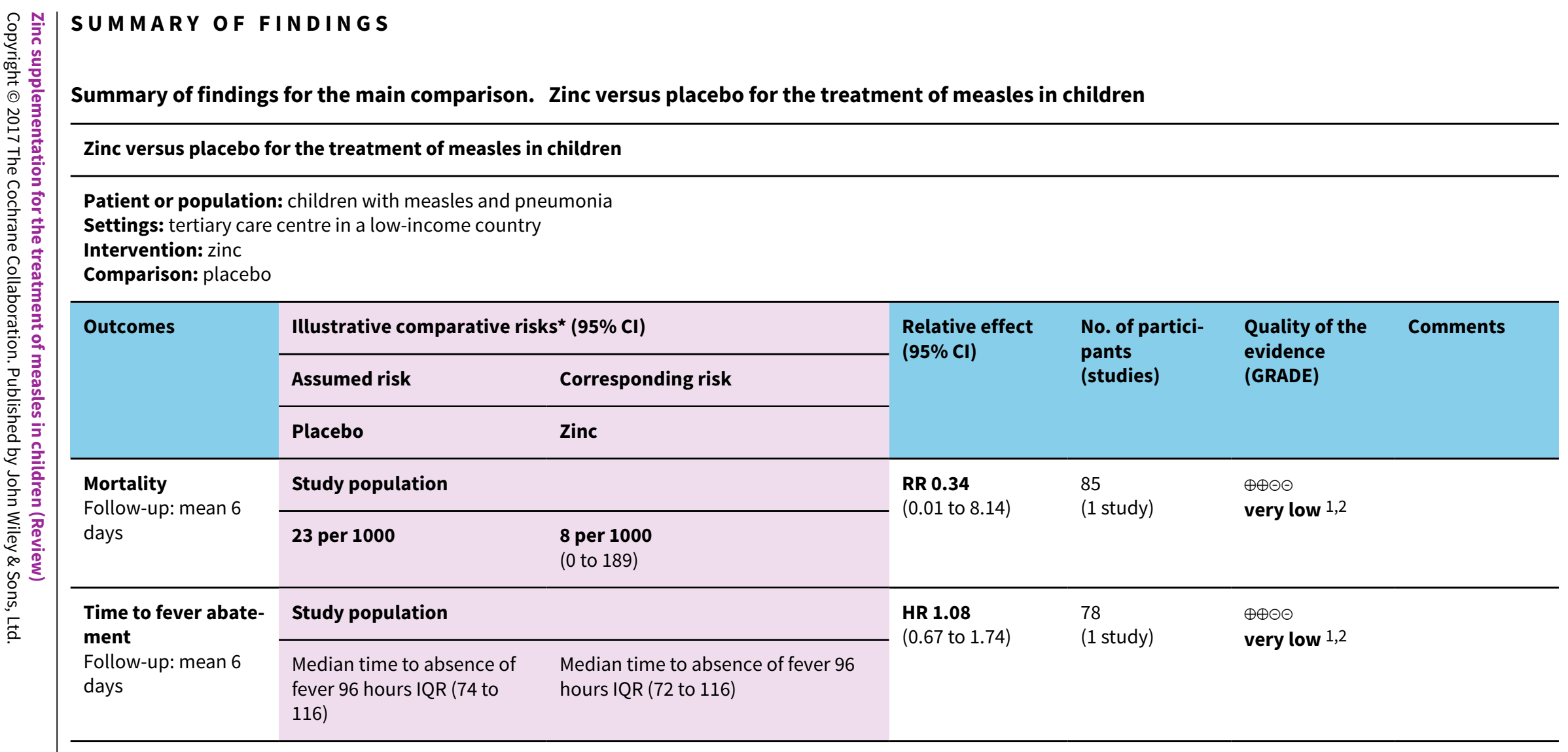

${ }^{*}$ The basis for the assumed risk (e.g. the median control group risk across studies) is provided in footnotes. The corresponding risk (and its $95 \%$ confidence interval) is based on the assumed risk in the comparison group and the relative effect of the intervention (and its $95 \% \mathrm{Cl}$ ).

Cl: confidence interval; HR: hazard ratio; IQR: interquartile range; RR: risk ratio

GRADE Working Group grades of evidence

High quality: Further research is very unlikely to change our confidence in the estimate of effect.

Moderate quality: Further research is likely to have an important impact on our confidence in the estimate of effect and may change the estimate.

Low quality: Further research is very likely to have an important impact on our confidence in the estimate of effect and is likely to change the estimate.

Very low quality: We are very uncertain about the estimate.

1Serious imprecision: wide confidence intervals, small sample size, and few events.

2Indirectness: study population differed clinically from children with uncomplicated measles. 


\section{B A C K G R O U N D}

\section{Description of the condition}

Measles is an important cause of childhood morbidity and mortality globally. It is a highly contagious acute viral infection characterised by high fever, cough, rhinitis, conjunctivitis, a rash on the mucous membranes, and a red maculopapular rash (Mason 2016). According to the World Health Organization, 535,000 children died of measles in 2000 (WHO 2012). Between 2000 and 2010, there was a $74 \%$ reduction in measles deaths globally as a result of improved vaccine coverage efforts (Simons 2012). However, large outbreaks occurred in Bulgaria in 2009 to 2010 and France in 2011 as a result of suboptimal immunisation levels (Carrillo-Santisteve 2012). Measles outbreaks occurred in Sierra Leone (between 2009 and 2010) and South Africa (between 2003 and 2005; 2009 and 2011), likely due to HIV infection and poor vaccine coverage (Sartorius 2013). Case fatality rates for measles among young children in low-income countries still hover at around 5\% to 6\% (Wolfson 2009). Acute lower respiratory infection is a common complication of measles, and is associated with mortality. Other important complications of measles include otitis media, laryngotracheobronchitis (croup), diarrhoea, encephalitis, and cortical damage leading to blindness (Perry 2004).

The global prevalence of zinc deficiency is estimated to be more than 20\% (Wuehler 2005), and in many low-income countries, is extremely prevalent among children (World Bank 2016). Most zinc is excreted through the gastrointestinal tract, therefore children who are regularly exposed to gastrointestinal pathogens and who have poor nutrition, low in animal products and high in phytate, are most at risk of zinc deficiency (Lazzerini 2016). Zinc deficiency results in the dysfunction of both humoral and cell-mediated immunity and increases susceptibility to infectious diseases such as diarrhoea and respiratory infection (Tuerk 2009). Respiratory tract infections, such as acute lower respiratory tract infections, are common complications of measles infection (Aggarwal 2007; Roth 2008; Shakur 2009).

\section{Description of the intervention}

Zinc is one of the most important trace elements in the human body. It is a component of over 1000 transcription factors and is required in more than 300 zinc-containing enzymes (Haase 2009; Stefanidou 2006). Zinc supplementation may reduce the duration of acute and persistent diarrhoea in children over six months of age (Lazzerini 2016), and frequency of diarrhoeal and respiratory illnesses in children (Aggarwal 2007). Zinc supplements can be given in the forms of zinc sulphate, zinc gluconate, zinc acetate, or zinc chloride. The recommended daily dose is $10 \mathrm{mg}$ to $20 \mathrm{mg}$ of zinc for children with diarrhoea (WHO/UNICEF 2004).

\section{How the intervention might work}

Several studies have demonstrated the importance of zinc in the maintenance of normal immune functions (Bach 1989; Prasad 1998; Prasad 2000; Prasad 2009; Stefanidou 2006; Tapiero 2003). Zinc is said to be crucial for effective innate and acquired immunity, and insufficient zinc status could be the most common cause of secondary immunodeficiency in humans (Tapiero 2003). Zinc deficiency impairs phagocytosis of macrophages and neutrophils, oxidative burst activity, and complement natural killer cell activity (Prasad 2000). Zinc is also involved in T-cell differentiation and enhancement of T-cell and natural killer cell actions through its role in thymulin activity (Bach 1989). In the absence of zinc, lymphocyte proliferation is depressed, as well as delayed-type hypersensitivity skin responses and T-cell dependent antigenantibody responses (Prasad 1998). Zinc has also been shown to have anti-inflammatory and antioxidant properties (Prasad 2009; Stefanidou 2006). Supplements increase the availability of zinc for these immunologic processes and may improve measles morbidity and mortality. In children, zinc supplementation is reported to reduce morbidity, mortality, and recovery time from acute infectious diseases (Cuevas 2005). Sazawal 2007 showed that zinc supplements given to children aged between 1 month and 48 months resulted in reduced mortality from acute infections including measles. Zinc supplementation has also been shown to significantly reduce respiratory morbidity in preschool children (Sazawal 1998), and may reduce the incidence of acute lower respiratory tract infections by improving measles morbidity.

\section{Why it is important to do this review}

Several reviews have shown that zinc supplementation is associated with reduced incidence and prevalence of pneumonia in children (Aggarwal 2007; Bhutta 1999; Lassi 2016). Other Cochrane Reviews evaluating zinc supplementation in children have looked at otitis media and diarrhoea (Gulani 2014; Lazzerini 2016). This review aimed to identify, critically appraise, and synthesise data from studies evaluating the effects of zinc supplementation in children with measles.

\section{O B JECTIVES}

To assess the effects of zinc supplementation in reducing morbidity and mortality in children with measles.

\section{METHODS}

\section{Criteria for considering studies for this review Types of studies}

Randomised controlled trials (RCTs) and quasi-RCTs evaluating the effects of zinc in reducing morbidity and mortality in children with measles.

\section{Types of participants}

Children aged up to 18 years diagnosed with measles.

\section{Types of interventions}

Zinc supplementation (irrespective of dosage, duration, and route of administration) combined with standard treatment compared with standard treatment alone or standard treatment with placebo. (Standard treatment was defined as relief of common symptoms such as fever, cough, blocked nose, conjunctivitis, and sore mouth; provision of nutritional support; and vitamin A (WHO 2004).)

\section{Types of outcome measures}

\section{Primary outcomes}

1. All-cause mortality.

\section{Secondary outcomes}

1. Duration of fever, coryza, cough, and rash.

2. Duration of hospitalisation. 
3. Incidence of complications such as pneumonia, otitis media, diarrhoea, and croup.

4. Effect on disability-adjusted life years.

5. Adverse events.

\section{Search methods for identification of studies}

\section{Electronic searches}

We searched the Cochrane Central Register of Controlled Trials (CENTRAL) (03 February 2017, Issue 2), which contains the Cochrane Acute Respiratory Infections Group Specialised Register, MEDLINE (1946 to 03 February 2017), Embase (1974 to 03 February 2017), CINAHL (Cumulative Index to Nursing and Allied Health Literature) (1981 to 03 February 2017), LILACS (Latin American and Caribbean Health Science Literature Database) (1982 to 03 February 2017), Web of Science (1985 to 03 February 2017), and BIOSIS Previews (1985 to 27 June 2014). We did not update the BIOSIS Previews search in February 2017 due to lack of institutional access to that database.

We used the search strategy described in Appendix 1 to search CENTRAL and MEDLINE. We combined the MEDLINE search with the Cochrane Highly Sensitive Search Strategy for identifying randomised trials in MEDLINE: sensitivity- and precisionmaximising version (2008 revision); Ovid format (Lefebvre 2011). We adapted the search strategy to search Embase (Appendix 2), CINAHL (Appendix 3), LILACS (Appendix 4), Web of Science (Appendix 5), and BIOSIS Previews (Appendix 6). We did not apply any language or publication restrictions.

\section{Searching other resources}

We searched ClinicalTrials.gov, the Australian New Zealand Clinical Trials Registry and the World Health Organization (WHO) International Clinical Trials Registry Platform (ICTRP) for unpublished and ongoing studies (latest search 03 February 2017). We scrutinised the reference lists of the included studies and relevant review articles for additional references.

\section{Data collection and analysis}

\section{Selection of studies}

Two review authors (AA, OO) independently screened the titles and abstracts of articles identified by the searches for eligibility. We classified these studies as 'included' or 'excluded'. We retrieved full-text articles of studies that did not have an abstract or had a limited abstract and assessed them for inclusion. Two review authors (AA, OO) independently assessed full-text articles classified as 'include' for inclusion in the review using a standardised form with explicit inclusion and exclusion criteria. Any disagreements were resolved by the two review authors. Only one study met our inclusion criteria.

\section{Data extraction and management}

Two review authors (AA, AS) independently extracted data from the included studies using a pre-designed data extraction form. We extracted the following information:

- general information (study ID, date of extraction, title, authors, and source of study if not published);

- study characteristics (study design, participants, and inclusion/ exclusion criteria used in the study);
- details of the interventions (including zinc dosage, treatment duration, comparison details, duration of follow-up);

- outcomes as described in Types of outcome measures above; and

- details necessary for 'Risk of bias' assessment.

We resolved disagreements by discussion.

\section{Assessment of risk of bias in included studies}

We identified no new studies in this update. For the 2015 version of this review, we used the 'Risk of bias' assessment tool and criteria set out in the Cochrane Handbook for Systematic Reviews of Interventions to assess the risk of bias for the included study (Higgins 2011). Two review authors (AA, AS) independently assessed the risk of bias of the included study by assessing randomisation sequence generation; allocation concealment; blinding of participants, personnel, and outcome assessors; incomplete outcome data; selective outcome reporting; and other sources of bias. We resolved disagreements through discussion. We reported results in a 'Risk of bias' table.

\section{Measures of treatment effect}

We presented results for dichotomous outcomes as risk ratio (RR) and hazard ratio (HR) with 95\% confidence intervals (CI) (as reported in the included study). For continuous outcomes, we intended to express the measure of effect as a mean difference (MD) with $95 \% \mathrm{Cl}$. However, data from the included study did not permit this analysis.

\section{Dealing with missing data}

We found attrition rates of $9.52 \%$ in the zinc arm and $11.62 \%$ in the placebo arm of the included study. We did not impute missing data.

\section{Assessment of heterogeneity}

We planned to assess statistical heterogeneity via visual inspection of forest plots of the included trials, using the $\mathrm{Chi}^{2}$ test and the $\mathrm{I}^{2}$ statistic, where data from included trials could be pooled. However, as there was only one included study, we could not conduct this assessment using the available data.

\section{Assessment of reporting biases}

We compared the list of outcomes in the methods section of the included study to the outcomes reported. We could not create an inverted funnel plot to check for possible publication bias because there were too few included studies.

\section{Data synthesis}

We entered data into Review Manager 5 software (RevMan 2014). As only one study was included in this review, data could not be combined for meta-analysis. We provided a narrative summary of findings for the included study.

\section{GRADE and 'Summary of findings' table}

We created a Summary of findings for the main comparison using the following outcomes: mortality and time to fever abatement. We used the five GRADE considerations (study limitations, consistency of effect, imprecision, indirectness, and publication bias) to assess the quality of evidence as it related to the included study (Atkins 2004). We used methods and recommendations described 
in Section 8.5 and Chapter 12 of the Cochrane Handbook for Systematic Reviews of Interventions (Higgins 2011), employing GRADEpro GDT software (GRADEpro GDT 2014). We justified decisions to downgrade study quality in footnotes, and made comments to aid readers understanding of the review where necessary.

\section{Subgroup analysis and investigation of heterogeneity}

We planned to explore any observed significant heterogeneity by conducting subgroup analyses based on the characteristics of participants (inpatient and outpatient, age group), type of comparison (placebo and standard treatment), type of supplement, dose and duration of supplement, and immunisation status. Due to insufficent data we were unable to conduct these analyses.

\section{Sensitivity analysis}

We planned to conduct sensitivity analyses to assess the impact of high risk of bias on meta-analysed outcomes by gradually adding studies with high risk of bias to pooled studies with low risk of bias. We did not perform these analyses due to insufficient data.

\section{RE S U L T S}

\section{Description of studies}

\section{Results of the search}

This is an update of a review first published in 2015. The most recent search (February 2017) did not identify any new studies for inclusion (Figure 1; Characteristics of included studies).

Figure 1. Study flow diagram.

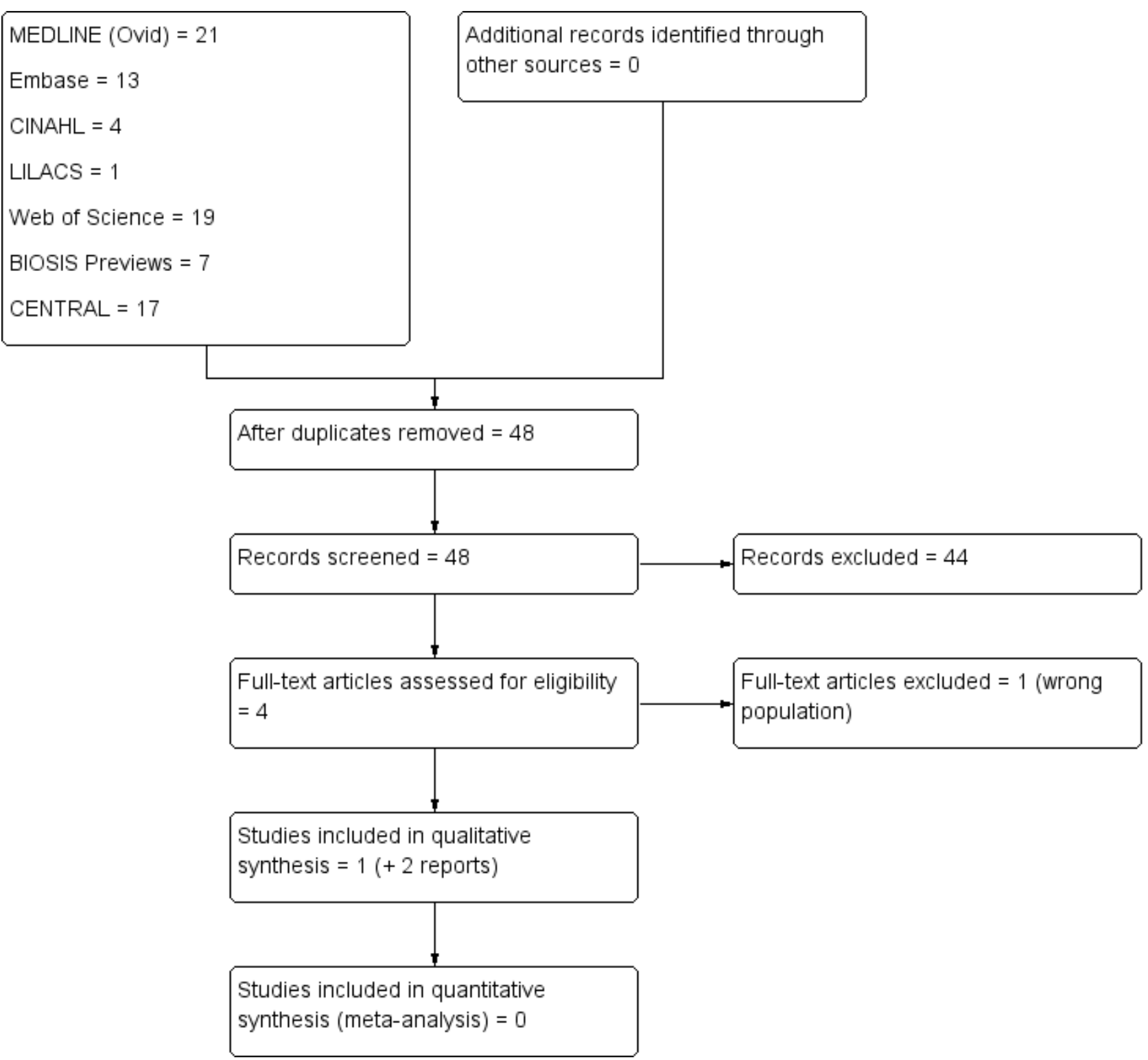

We retrieved 48 records from the searches of electronic databases. We found no ongoing studies in the following trial registries:
ClinicalTrials.gov, the Australian New Zealand Clinical Trials Registry, and the WHO ICTRP. Two review authors (AA, OO)

Zinc supplementation for the treatment of measles in children (Review) 
independently scanned titles and abstracts using prespecified inclusion criteria. We identified four potentially eligible studies and obtained full-text articles. One study met our inclusion criteria and was included in the review. We provided reasons for excluding a potentially eligible study (see Characteristics of excluded studies).

\section{Included studies}

We included one RCT (three reports) that compared zinc supplement with placebo (Mahalanabis 2002). This was a doubleblind, randomised, placebo-controlled trial carried out in a tertiary care hospital in India. There were 85 participants: 42 in the zinc group and 43 in the placebo group. Participants were children admitted to the hospital with an illness that was compatible with measles (generalised maculopapular rash with fever and at least one of the following: cough, coryza, or conjunctivitis and a clinical diagnosis of acute lower respiratory tract infection (pneumonia)). Children who had congenital anomalies, chronic diseases, or severe malnutrition were excluded from the study.

Mahalanabis 2002 compared a zinc acetate mixture containing 20 $\mathrm{mg}$ elemental zinc with placebo, each given twice daily for six days. All trial participants also received a single dose of vitamin A and antibiotics. The duration of therapy and follow-up was six days. The study aimed to compare the clinical status (duration of significant illness, fever and tachypnoea) of participants in the zinc and placebo groups. The study also assessed serum zinc and retinol concentrations. Mahalanabis 2002 used the $\mathrm{Chi}^{2}$ test or Fisher's exact test as well as survival analysis (Cox proportional hazards model) to compare groups. $P$ values were reported.

The baseline characteristics of children in the zinc and placebo groups were similar. These included age, gender, duration of measles rash, weight-for-age (z score), height-for-age (z score), and difficulty in eating or feeding (\%). Five participants in the placebo arm and three in the zinc arm withdrew from the study; one child in the zinc arm dropped out on day one due to breakage of the bottle containing the supplement. One child in the control group, who was admitted in a coma and diagnosed clinically with septicaemia, died.

\section{Excluded studies}

We excluded one study: Tielsch 2007 included children who did not have measles (see Characteristics of excluded studies).

\section{Risk of bias in included studies}

We assessed risk of bias in the included study using the Cochrane 'Risk of bias' tool for RCTs (Figure 2). We assessed risk of bias as low for most domains, and unclear for selective reporting. 
Figure 2. 'Risk of bias' summary: review authors' judgements about each risk of bias item for each included study.

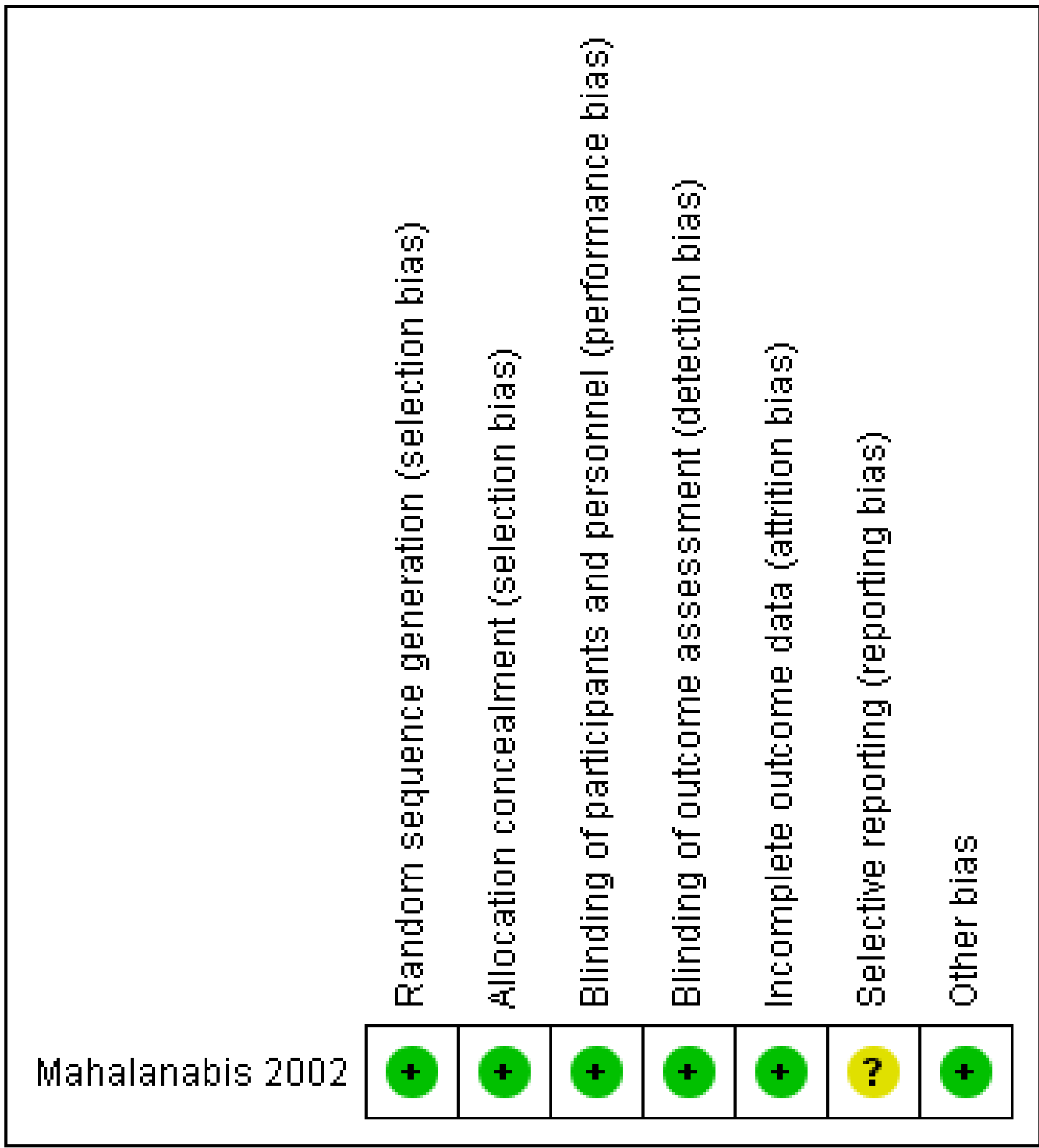

\section{Allocation}

Allocation of participants to receive either the zinc supplement or placebo was done using permuted blocks of random numbers to create a master randomisation schedule. The allocation sequence was concealed using serially numbered, identical bottles. We assessed Mahalanabis 2002 as at low risk of bias for this domain.

\section{Blinding}

Participants received serially numbered bottles, which contained mixtures that were identical in colour, consistency, and taste, ensuring adequate blinding. We assessed Mahalanabis 2002 as at low risk of bias for this domain.

\section{Incomplete outcome data}

Losses to follow-up were similar in both the intervention and control groups. The attrition rates were $9.52 \%$ in the zinc group and 
$11.62 \%$ in the placebo group. We assessed Mahalanabis 2002 as at low risk of bias for this domain.

\section{Selective reporting}

We could not locate a registered trial protocol to compare the prespecified outcomes with the outcomes reported in the manuscript. We assessed Mahalanabis 2002 as at unclear risk of bias for this domain.

\section{Other potential sources of bias}

We did not identify any other potential sources of bias.

\section{Effects of interventions}

See: Summary of findings for the main comparison Zinc versus placebo for the treatment of measles in children
Mahalanabis 2002 reported the following outcomes: median (quartiles) time required for resolution of fever and tachypnoea, return of appetite, and achievement of a much improved or cured status. This review proposed assessment of a number of other outcomes that were not reported by Mahalanabis 2002: duration of coryza, cough, and rash; incidence of complications such as pneumonia, otitis media, diarrhoea, and croup; and effect on disability-adjusted life years.

\section{Primary outcome}

\section{All-cause mortality}

There was no statistically significant difference in all-cause mortality between children in the zinc supplementation plus standard treatment group and children in the placebo plus standard treatment group (RR $0.34,95 \% \mathrm{Cl} 0.01$ to 8.14; $\mathrm{P}=0.51$; Analysis 1.1; Figure 3).

Figure 3. Forest plot of comparison: 1 Zinc versus placebo, outcome: 1.1 Mortality.

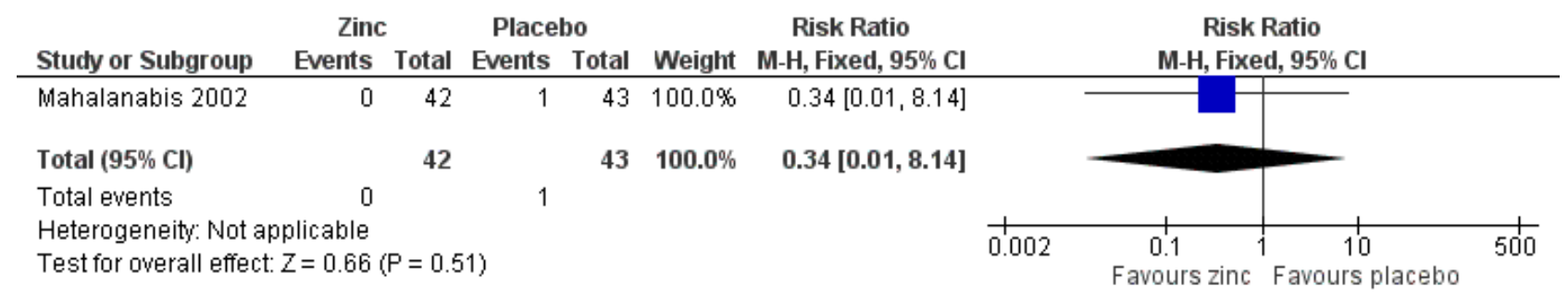

\section{Secondary outcomes}

\section{Duration of fever, coryza, cough, and exanthema (rash)}

Zinc supplementation in children with measles showed a nonsignificant effect on time to absence of fever compared to the placebo group (HR 1.08, 95\% Cl 0.67 to 1.74 , fixed-effect model; $\mathrm{P}=$ 0.75; Analysis 1.2; Figure 4).

Figure 4. Forest plot of comparison: 1 Zinc versus placebo, outcome: 1.2 Time to fever abatement.

\begin{tabular}{|c|c|c|c|c|c|c|c|c|c|c|}
\hline Study or Subgroup & log[Hazard Ratio] & SE & $\begin{array}{l}\text { Zinc } \\
\text { Total }\end{array}$ & $\begin{array}{r}\text { Placebo } \\
\text { Total } \\
\end{array}$ & Weight & $\begin{array}{l}\text { Hazard Ratio } \\
\text { IV, Fixed, 95\% Cl }\end{array}$ & & $\begin{array}{c}\text { Hazard Ratio } \\
\text { IV, Fixed, 95\% Cl }\end{array}$ & & \\
\hline Mahalanabis 2002 & 0.07696 & 0.24346 & 40 & 38 & $100.0 \%$ & $1.08[0.67,1.74]$ & & & & \\
\hline Total $(95 \% \mathrm{Cl})$ & & & 40 & 38 & $100.0 \%$ & $1.08[0.67,1.74]$ & & & & \\
\hline $\begin{array}{l}\text { Heterogeneity: Not a } \\
\text { Test for overall effect }\end{array}$ & $\begin{array}{l}\text { plicable } \\
Z=0.32(P=0.75)\end{array}$ & & & & & & 0.05 & $\begin{array}{cc}1 & 1 \\
0.2 & 1 \\
\text { Favours zinc } & \text { Favours }\end{array}$ & $\begin{array}{l}1 \\
5 \\
\text { placebo }\end{array}$ & 20 \\
\hline
\end{tabular}

\section{Duration of hospitalisation}

All children enrolled were hospitalised for the study duration (Mahalanabis 2002).

\section{Incidence of complications such as pneumonia, otitis media, diarrhoea, and croup}

Mahalanabis 2002 did not report the incidence of complications.

\section{Effect on disability-adjusted life years}

Mahalanabis 2002 did not report the effect on disability-adjusted life years.

\section{Adverse events}

Mahalanabis 2002 did not report any treatment-related side effects in either group.

\section{ISCUSSION}

\section{Summary of main results}

This is an update of a review first published in 2015 and included no new studies. Previous conclusions are unchanged.

The included study involved 85 children: 42 received a zinc acetate mixture containing $20 \mathrm{mg}$ elemental zinc, and 43 received placebo (Mahalanabis 2002). All children were diagnosed with measles and pneumonia and all received vitamin A and antibiotics. One child in the placebo group died during the trial.

Mahalanabis 2002 demonstrated no significant difference in duration of fever between groups. All enrolled children were hospitalised for the entire duration of the study. No treatmentrelated side effects were reported in either group. 


\section{Overall completeness and applicability of evidence}

We conducted a comprehensive search to identify all relevant studies that met our inclusion criteria. We found only one study that met the inclusion criteria. There was no significant difference in outcomes reported between groups in the included study (Mahalanabis 2002).

The evidence for this review was drawn from a single small study that was not adequately powered. Mahalanabis 2002 was conducted in a tertiary healthcare setting in India. We are not confident about the observed effect estimates because of imprecision of the results. It is therefore difficult to comment on the applicability of the available evidence.

\section{Quality of the evidence}

We used the GRADE approach to assess the quality of the evidence in this review (GRADEpro GDT 2014; Higgins 2011; Schünemann 2011). We carried out one comparison: zinc acetate versus placebo for children with measles for two outcomes (mortality and reduction of fever duration). We downgraded the quality of the evidence based on imprecision of the effect estimates (small sample size and few events) and indirectness. We assessed the quality of the evidence as very low. We are therefore very uncertain about the estimate.

\section{Potential biases in the review process}

We identified one RCT for inclusion using the comprehensive search strategy developed by the Cochrane Acute Respiratory Infections Group. We applied no language or publication limitations. We also searched three clinical trial registries and did not find any ongoing trials. Other potential biases were limited by ensuring that two review authors independently conducted the study selection, quality assessment, and data extraction.

\section{Agreements and disagreements with other studies or reviews}

A previous Cochrane Review did not find sufficient evidence to support use of zinc as an adjunct to standard antibiotic therapy for pneumonia in children aged 2 months to 35 months (Haider 2011). Another Cochrane Review concluded that zinc supplementation in children is associated with a reduction in the incidence and prevalence of pneumonia (Lassi 2016).

\section{AUTHORS' CONCLUSIONS}

\section{Implications for practice}

We could draw no definitive conclusions from this review about the effects of zinc supplementation on clinical outcomes for children with measles due to the very low quality of the available evidence. The current evidence is not conclusive and neither supports nor refutes the use of zinc supplementation in children with measles.

\section{Implications for research}

Adequately powered studies addressing clinically relevant outcomes such as age-specific mortality, incidence of complications (such as pneumonia, otitis media, diarrhoea, and croup), and the effect on disability-adjusted life years are required for better assessment of the impact of zinc supplementation in children with measles.

\section{ACKNOWLEDGEMENTS}

This research project was conducted as part of the academic requirements of the MSc in Clinical Epidemiology, Stellenbosch University (www.sun.ac.za/clinepi).

We thank Sarah Thorning for her help with the search strategy. We also thank the following people for commenting on the draft of this review: Derek Ansel, Theresa Wrangham, Robert Black, Elaine Beller, and Taixiang Wu. 


\section{R E F E R E N C E S}

\section{References to studies included in this review}

Mahalanabis 2002 \{published data only\}

Khaled MA, Mahalanabis D, Jana S, Chowdhury MK, Haque KM, Das KP. Zinc supplementation and lipid peroxidation in children with measles and pneumonia. FASEB Journal 2001;15:A610.

* Mahalanabis D, Chowdhury A, Jana S, Bhattacharya MK, Chakrabarti MK, Wahed MA, et al. Zinc supplementation as adjunct therapy in children with measles accompanied by pneumonia: a double-blind, randomized controlled trial. American Journal of Clinical Nutrition 2002;76(3):604-7. [PUBMED: 12198006]

Mahalanabis D, Chowdhury A, Jana S, Bhattacharya MK, Chakrabarty MK, Wahed MA, et al. Zinc supplementation of children suffering from measles with pneumonia: effect on diseases severity. FASEB Journal 2001;15(5):A1094.

\section{References to studies excluded from this review}

Tielsch 2007 \{published data only\}

Tielsch JM, Khatry SK, Stoltzfus RJ, Katz J, LeClerq SC, Adhikari R, et al. Effect of daily zinc supplementation on child mortality in southern Nepal: a community-based, cluster randomised, placebo-controlled trial. Lancet 2007;370(9594):1230-9. [PUBMED: 17920918]

\section{Additional references}

\section{Aggarwal 2007}

Aggarwal R, Sentz J, Miller MA. Role of zinc administration in prevention of childhood diarrhea and respiratory illnesses: a meta-analysis. Pediatrics 2007;119(6):1120-30. [PUBMED: 17545379]

\section{Atkins 2004}

Atkins D, Best D, Briss PA, Eccles M, Falck-Ytter Y, Flottorp S, et al. GRADE Working Group. Grading quality of evidence and strength of recommendations. BMJ 2004;328(7454):1490.

\section{Bach 1989}

Bach JF, Dardenne M. Thymulin, a zinc-dependent hormone. Medical Oncology and Tumor Pharmacotherapy 1989;6(1):25-9. [PUBMED: 2657247]

\section{Bhutta 1999}

Bhutta ZA, Black RE, Brown KH, Gardner JM, Gore S, Hidayat A, et al. Prevention of diarrhea and pneumonia by zinc supplementation in children in developing countries: pooled analysis of randomized controlled trials. Zinc Investigators' Collaborative Group. Journal of Pediatrics 1999;135(6):689-97. [PUBMED: 10586170]

\section{Carrillo-Santisteve 2012}

Carrillo-Santisteve P, Lopalco PL. Measles still spreads in Europe: who is responsible for the failure to vaccinate?. Clinical Microbiology and Infection 2012;18(Suppl 5):50-6. [PUBMED: 23051058]

\section{Cuevas 2005}

Cuevas LE, Koyanagi A. Zinc and infection: a review. Annals of Tropical Paediatrics 2005;25(3):149-60. [PUBMED: 16156979]

\section{GRADEpro GDT 2014 [Computer program]}

GRADE Working Group, McMaster University. GRADEpro GDT. Version (accessed October 2014). Hamilton (ON): GRADE Working Group, McMaster University, 2014.

\section{Gulani 2014}

Gulani A, Sachdev HS. Zinc supplements for preventing otitis media. Cochrane Database of Systematic Reviews 2014, Issue 6. [DOI: 10.1002/14651858.CD006639.pub4]

\section{Haase 2009}

Haase H, Rink L. Functional significance of zinc-related signaling pathways in immune cells. Annual Review of Nutrition 2009;29:133-52. [PUBMED: 19400701]

\section{Haider 2011}

Haider BA, Lassi ZS, Ahmed A, Bhutta ZA. Zinc supplementation as an adjunct to antibiotics in the treatment of pneumonia in children 2 to 59 months of age. Cochrane Database of Systematic Reviews 2011, Issue 10. [DOI: 10.1002/14651858.CD007368.pub2]

\section{Higgins 2011}

Higgins JP, Green S (editors). Cochrane Handbook for Systematic Reviews of Interventions Version 5.1.0 (updated March 2011). The Cochrane Collaboration, 2011. Available from handbook.cochrane.org.

\section{Lassi 2016}

Lassi ZS, Moin A, Bhutta ZA. Zinc supplementation for the prevention of pneumonia in children aged 2 months to 59 months. Cochrane Database of Systematic Reviews 2016, Issue 12. [DOI: 10.1002/14651858.CD005978.pub3]

\section{Lazzerini 2016}

Lazzerini M, Wanzira $\mathrm{H}$. Oral zinc for treating diarrhoea in children. Cochrane Database of Systematic Reviews 2016, Issue 12. [DOI: 10.1002/14651858.CD005436.pub5]

\section{Lefebvre 2011}

Lefebvre C, Manheimer E, Glanville J. Chapter 6: Searching for studies. In: Higgins JP, Green S (editors). Cochrane Handbook for Systematic Reviews of Interventions Version 5.1.0 (updated March 2011). The Cochrane Collaboration, 2011. Available from handbook.cochrane.org.

\section{Mason 2016}

Mason WH. Measles. In: Kliegman RM, Stanton BF, St Geme JW, Shor NF editor(s). Nelson Textbook of Pediatrics. 20th Edition. Elsevier Science (USA), 2016.

\section{Perry 2004}

Perry RT, Halsey NA. The clinical significance of measles: a review. Journal of Infectious Diseases 2004;189(Suppl 1):4-16. [PUBMED: 15106083] 


\section{Prasad 1998}

Prasad AS. Zinc and immunity. Molecular and Cellular Biochemistry 1998;188(1-2):63-9. [PUBMED: 9823012]

\section{Prasad 2000}

Prasad AS. Effects of zinc deficiency on immune functions. Journal of Trace Elements in Experimental Medicine 2000;13(1):1-20.

\section{Prasad 2009}

Prasad AS. Zinc: role in immunity, oxidative stress and chronic inflammation. Current Opinion in Clinical Nutrition and Metabolic Care 2009;12(6):646-52. [PUBMED: 19710611]

\section{RevMan 2014 [Computer program]}

Nordic Cochrane Centre, The Cochrane Collaboration. Review Manager 5. Version 5.3. Copenhagen: Nordic Cochrane Centre, The Cochrane Collaboration, 2014.

\section{Roth 2008}

Roth DE, Caulfield LE, Ezzati M, Black RE. Acute lower respiratory infections in childhood: opportunities for reducing the global burden through nutritional interventions. Bulletin of the World Health Organization 2008;86(5):356-64. [PUBMED: 18545738]

\section{Sartorius 2013}

Sartorius B, Cohen C, Chirwa T, Ntshoe G, Puren A, Hofman K. Identifying high-risk areas for sporadic measles outbreaks: lessons from South Africa. Bulletin of the World Health Organization 2013;91(3):174-83. [PUBMED: 23476090]

\section{Sazawal 1998}

Sazawal S, Black RE, Jalla S, Mazumdar S, Sinha A, Bhan MK. Zinc supplementation reduces the incidence of acute lower respiratory infections in infants and preschool children: a double-blind, controlled trial. Pediatrics 1998;102:1-5.

\section{Sazawal 2007}

Sazawal S, Black RE, Ramsan M, Chwaya HM, Dutta A, Dhingra U, et al. Effect of zinc supplementation on mortality in children aged 1-48 months: a community-based randomised placebocontrolled trial. Lancet 2007;369(9565):927-34. [PUBMED: 17368154]

\section{Schünemann 2011}

Schünemann HJ, Oxman AD, Vist GE, Higgins JP, Deeks JJ, Glasziou P. Chapter 12: Interpreting results and drawing conclusions. In: Higgins JP, Green S (editors). Cochrane Handbook for Systematic Reviews of Interventions Version 5.1.0 (updated March 2011). The Cochrane Collaboration, 2011. Available from handbook.cochrane.org.

\section{Shakur 2009}

Shakur MS, Malek MA, Bano N, Rahman M, Ahmed M. Serum and hair zinc in severely malnourished Bangladeshi children associated with or without acute lower respiratory infection. Indian Journal of Pediatrics 2009;76(6):609-14. [PUBMED: 19381511]

\section{Simons 2012}

Simons E, Ferrari M, Fricks J, Wannemuehler K, Anand A, Burton A, et al. Assessment of the 2010 global measles mortality reduction goal: results from a model of surveillance data. Lancet 2012;379(9832):2173-8. [PUBMED: 22534001]

\section{Stefanidou 2006}

Stefanidou M, Maravelias C, Dona A, Spiliopoulou C. Zinc: a multipurpose trace element. Archives of Toxicology 2006;80(1):1-9. [PUBMED: 16187101]

\section{Tapiero 2003}

Tapiero H, Tew KD. Trace elements in human physiology and pathology: zinc and metallothioneins. Biomedicine and Pharmacotherapy 2003;57(9):399-411. [PUBMED: 14652165]

\section{Tuerk 2009}

Tuerk MJ, Fazel N. Zinc deficiency. Current Opinion in Gastroenterology 2009;25(2):136-43. [PUBMED: 19528881]

\section{WHO 2004}

World Health Organization. Treating measles in children. www.who.int/immunization_delivery/interventions/ TreatingMeaslesENG300.pdf 2004 (accessed 27 November 2013).

\section{WHO 2012}

World Health Organization. Global measles and rubella strategic plan: 2012 - 2020. Geneva: World Health Organization, 2012.

\section{WHO/UNICEF 2004}

World Health Organization. Department of Child and Adolescent Health and Development/United Nations International Children's Emergency Fund. Clinical management of acute diarrhoea: WHO/UNICEF joint statement [WHO/FCH/CAH/04.7; UNICEF/PD/Diarrhoea/01]. whqlibdoc.who.int/hq/2004/ WHO_FCH_CAH_04.7.pdf 2004 (accessed 27 November 2013).

\section{Wolfson 2009}

Wolfson LJ, Grais RF, Luquero FJ, Birmingham ME, Strebel PM. Estimates of measles case fatality ratios: a comprehensive review of community-based studies. International Journal of Epidemiology 2009;38(1):192-205.

\section{World Bank 2016}

International Bank for Reconstruction and Development. World Bank list of economies. www.ispo2017.org/wp-content/ uploads/2016/11/World-Bank-List-of-Economies.pdf 2016 (accessed 10 May 2017).

\section{Wuehler 2005}

Wuehler SE, Peerson JM, Brown KH. Use of national food balance data to estimate the adequacy of zinc in national food supplies: methodology and regional estimates. Public Health Nutrition 2005;8(7):812-9. [PUBMED: 16277796] 


\section{References to other published versions of this review}

\section{Awotiwon 2014}

Awotiwon AA, Oduwole O, Sinha A, Okwundu CI. Zinc supplementation for the treatment of measles in children. Cochrane Database of Systematic Reviews 2014, Issue 6. [DOI: 10.1002/14651858.CD011177]

\section{CHARACTERISTICS OF STUDIES}

Characteristics of included studies [ordered by study ID]

Mahalanabis 2002

\begin{tabular}{|c|c|}
\hline Methods & $\begin{array}{l}\text { Study design: randomised, placebo-controlled trial } \\
\text { Study duration: } 6 \text { days (dates not reported) }\end{array}$ \\
\hline Participants & $\begin{array}{l}\text { Inclusion criteria } \\
\text { - Setting: tertiary care hospital } \\
\text { - Country: India } \\
\text { - Health status: children admitted to the hospital with an illness that was compatible with measles and } \\
\text { a clinical diagnosis of acute lower respiratory infection (pneumonia) } \\
\text { - Number: zinc + supportive care }(\mathrm{N}=42) \text {; placebo + supportive care }(\mathrm{N}=43) \\
\text { - Age: } 9 \text { months to } 15 \text { years } \\
\text { - Sex (M/F): zinc group }(18 / 24) ; \text { placebo }(25 / 18) \\
\text { Exclusion criteria } \\
\text { - Congenital anomalies } \\
\text { - Chronic diseases } \\
\text { - Severe malnutrition }\end{array}$ \\
\hline
\end{tabular}

\section{Awotiwon 2015}

Awotiwon AA, Oduwole O, Sinha A, Okwundu Cl. Zinc supplementation for the treatment of measles in children. Cochrane Database of Systematic Reviews 2015, Issue 3. [DOI: 10.1002/14651858.CD011177.pub2]

* Indicates the major publication for the study

\section{Zinc group}

- Zinc acetate mixture containing 20 mg elemental zinc given twice daily for 6 days

- Vitamin A and antibiotics

\section{Placebo group}

- Syrup-based mixture given twice daily for 6 days

- Vitamin A and antibiotics

Outcomes The main outcome of the study was the clinical status of the participants. Serum zinc and retinol concentrations were also assessed.

Notes The study protocol was approved by the hospital's ethics committee.

Funding: The study was funded by the Child Health Foundation (USA) and the Nestlé Foundation.

\section{Risk of bias}

\begin{tabular}{lll}
\hline Bias & Authors' judgement & Support for judgement \\
\hline $\begin{array}{l}\text { Random sequence genera- } \\
\text { tion (selection bias) }\end{array}$ & Low risk & $\begin{array}{l}\text { Permuted blocks of random numbers to create a master randomisation sched- } \\
\text { ule }\end{array}$ \\
\hline
\end{tabular}


Mahalanabis 2002 (Continued)

Allocation concealment Low risk
(selection bias)

\begin{tabular}{|c|c|c|}
\hline $\begin{array}{l}\text { Blinding of participants } \\
\text { and personnel (perfor- } \\
\text { mance bias) } \\
\text { All outcomes }\end{array}$ & Low risk & $\begin{array}{l}\text { Serially numbered bottles that contained mixtures that were identical in } \\
\text { colour, consistency, and taste, ensuring adequate blinding. } \\
\text { An independent pharmaceutical chemist ensured adequate blinding of the pri- } \\
\text { mary investigators. }\end{array}$ \\
\hline $\begin{array}{l}\text { Blinding of outcome as- } \\
\text { sessment (detection bias) } \\
\text { All outcomes }\end{array}$ & Low risk & $\begin{array}{l}\text { The evaluating physician had no knowledge of the treatment group to which } \\
\text { any of the children belonged. }\end{array}$ \\
\hline $\begin{array}{l}\text { Incomplete outcome data } \\
\text { (attrition bias) } \\
\text { All outcomes }\end{array}$ & Low risk & Attrition rates were $9.52 \%$ in the zinc group and $11.62 \%$ in the placebo group. \\
\hline $\begin{array}{l}\text { Selective reporting (re- } \\
\text { porting bias) }\end{array}$ & Unclear risk & No protocol with prespecified outcomes identified. \\
\hline Other bias & Low risk & None \\
\hline
\end{tabular}

\section{Characteristics of excluded studies [ordered by study ID]}

\begin{tabular}{ll}
\hline Study & Reason for exclusion \\
\hline Tielsch 2007 & $\begin{array}{l}\text { This was a community-based, cluster-randomised, double-masked, placebo-controlled } 2 \times 2 \text { factor- } \\
\text { ial trial in children aged } 1 \text { to } 35 \text { months. The study participants did not have measles. }\end{array}$ \\
\hline
\end{tabular}

\section{DATA AND ANALYSES}

\section{Comparison 1. Zinc versus placebo}

\begin{tabular}{lllll}
\hline Outcome or subgroup title & No. of studies & $\begin{array}{l}\text { No. of partici- } \\
\text { pants }\end{array}$ & Statistical method & Effect size \\
\hline 1 Mortality & 1 & 85 & Risk Ratio (M-H, Fixed, 95\% Cl) & $0.34[0.01,8.14]$ \\
\hline 2 Time to fever abatement & 1 & 78 & Hazard Ratio (Fixed, 95\% Cl) & $1.08[0.67,1.74]$ \\
\hline
\end{tabular}

Analysis 1.1. Comparison 1 Zinc versus placebo, Outcome 1 Mortality.

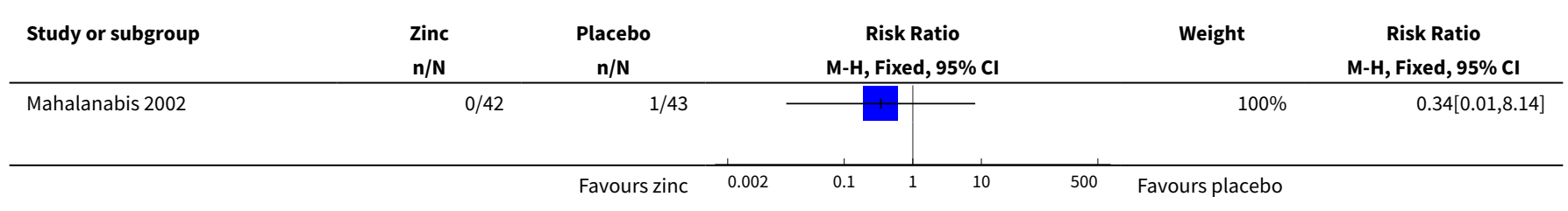




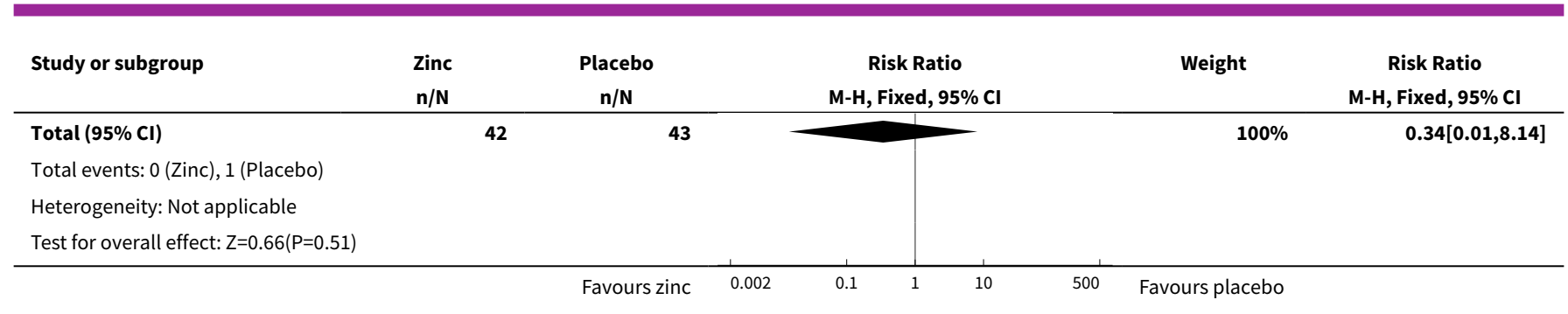

Analysis 1.2. Comparison 1 Zinc versus placebo, Outcome 2 Time to fever abatement.

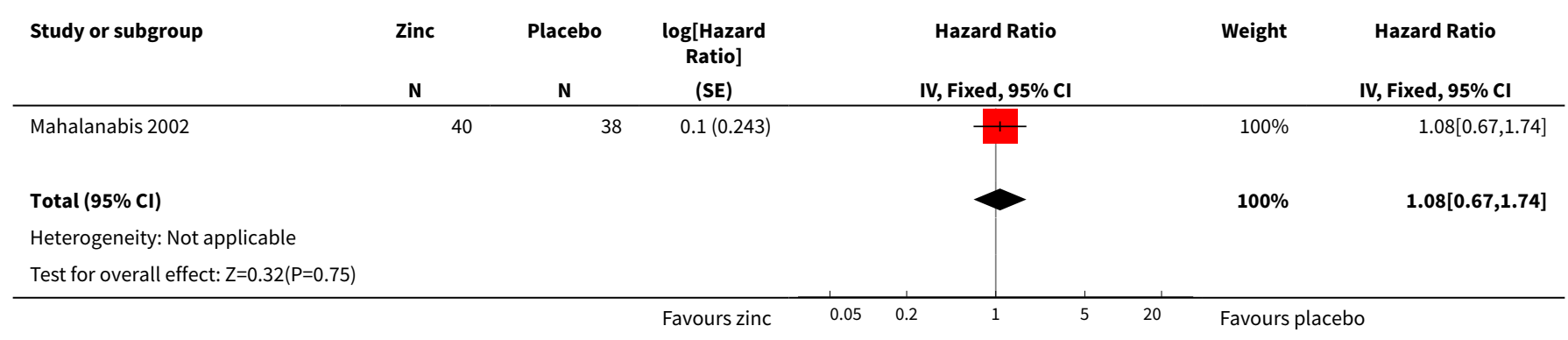

\section{APPENDICES}

\section{Appendix 1. MEDLINE (Ovid) search strategy}

1 exp Measles/

2 exp Measles virus/

3 Morbillivirus Infections/

4 Morbillivirus/

5 (measles $^{*}$ or rubeola*).tw.

6 or $/ 1-5$

7 exp Zinc/

8 exp Zinc Acetate/

9 Zinc Sulfate/

10 exp Zinc Compounds/

11 (zinc or zn).tw,nm.

12 Trace Elements/

13 Dietary Supplements/

14 or/7-13

156 and 14

\section{Appendix 2. Embase (Elsevier) search strategy}

\#1.14 \#1.5 AND \#1.13 87

\#1.13 \#1.6 OR \#1.7 OR \#1.8 OR \#1.9 OR \#1.10 OR \#1.11 OR \#1.12

\#1.12 zinc:ab,ti OR zn:ab,ti AND [embase]/lim

\#1.11 'zinc derivative'/de AND [embase]/lim 

\#1.10 'zinc chloride'/de AND [embase]/lim
\#1.9 'gluconate zinc'/de AND [embase]/lim
\#1.8 'zinc sulfate'/de AND [embase]/lim
\#1.7 'zinc acetate'/de AND [embase]/lim
\#1.6 'zinc'/de AND [embase]/lim
\#1.5 \#1.1 OR \#1.2 OR \#1.3 OR \#1.4
\#1.4 measles:ab,ti OR rubeola:ab,ti AND [embase]/lim
\#1.3 'morbillivirus infection'/de AND [embase]/lim
\#1.2 'measles virus'/de AND [embase]/lim
\#1.1 'measles'/de AND [embase]/lim

\section{\#2.8 \#2.3 NOT \#2.7881901}

\section{\#2.7 \#2.4 NOT \#2.6}

\#2.6 \#2.4 AND \#2.5

\#2.5 'human'/de AND [embase]/lim

\#2.4 'animal'/de OR 'nonhuman'/de OR 'animal experiment'/de AND

[embase]/lim

\section{\#2.3 \#2.1 OR \#2.2}

\#2.2 random*:ab,ti OR placebo*:ab,ti OR crossover*:ab,ti OR 'cross over':ab,ti OR allocat*:ab,ti OR trial:ti OR (doubl* NEXT/1 blind $\left.{ }^{\star}\right)$ :ab,ti AND [embase]/lim

\#2.1 'randomized controlled trial'/exp OR 'single blind procedure'/ exp OR 'double blind procedure'/exp OR 'crossover procedure'/exp AND [embase]/lim

\#3 \#1 AND \#2

\section{Appendix 3. CINAHL (Ebsco) search strategy}

S1 (MH "Measles+")

S2 TI (measles or rubeola) OR AB (measles or rubeola)

S3 S1 OR S2

S4 (MH "Zinc")

S5 (MH "Zinc Compounds+")

S6 (MH "Trace Elements")

S7 (MH "Dietary Supplements")

S8 TI (zinc or zn) OR AB (zinc or zn)

S9 S4 OR S5 OR S6 OR S7 OR S8

Zinc supplementation for the treatment of measles in children (Review) 
S10 S3 AND S9

\section{Appendix 4. LILACS (BIREME) search strategy}

w:((mh:measles OR measles OR sarampión OR sarampo OR rubeola OR mh:c02.782.580.600.500.500* OR mh:"Measles virus" OR mh:b04.820.455.600.650.500.500* OR mh:b04.909.777.455.600.650.500.500* OR mh:"Morbillivirus Infections" OR mh:morbillivirus) AND (mh:zinc OR zinc OR zinco OR mh:"Zinc Compounds" OR mh:d01.975* OR mh:"Zinc Acetate" OR zn OR mh:"Trace Elements" OR mh:"Dietary Supplements")) AND (instance:"regional") AND ( type_of_study:("clinical_trials"))

\section{Appendix 5. Web of Science (Thomas Reuters) search strategy}

\begin{tabular}{|c|c|}
\hline$\# 1$ & $\begin{array}{l}\text { TOPIC: (measles or rubeola) } \\
\text { Indexes=SCI-EXPANDED, SSCI, A\&HCI, CPCI-S, CPCI-SSH, CCR-EXPANDED, IC } \\
\text { Timespan=All years }\end{array}$ \\
\hline \#2 & $\begin{array}{l}\text { TOPIC: (zinc or zn) } \\
\text { Indexes=SCI-EXPANDED, SSCI, A\&HCI, CPCI-S, CPCI-SSH, CCR-EXPANDED, IC } \\
\text { Timespan=All years }\end{array}$ \\
\hline \#3 & $\begin{array}{l}\# 2 \text { AND \#1 } \\
\text { Indexes=SCI-EXPANDED, SSCI, A\&HCI, CPCI-S, CPCI-SSH, CCR-EXPANDED, IC } \\
\text { Timespan=All years }\end{array}$ \\
\hline \#4 & $\begin{array}{l}\text { TOPIC: (random* or placebo* or crossover* or "cross over" or allocat* or } \\
\text { ((singl* or doubl*) NEAR/1 blind*)) OR TITLE: (trial) } \\
\text { Indexes=SCI-EXPANDED, SSCI, A\&HCI, CPCI-S, CPCI-SSH, CCR-EXPANDED, IC } \\
\text { Timespan=All years }\end{array}$ \\
\hline \#5 & $\begin{array}{l}\# 4 \text { AND \#3 } \\
\text { Indexes=SCI-EXPANDED, SSCI, A\&HCI,CPCI-S, CPCI-SSH, CCR-EXPANDED, IC } \\
\text { Timespan=All years }\end{array}$ \\
\hline
\end{tabular}

Appendix 6. BIOSIS Previews (Thomson Reuters) search strategy

\begin{tabular}{|c|c|}
\hline \#1 & $\begin{array}{l}\text { TOPIC: (measles or rubeola) } \\
\text { Indexes }=B I O S I S \text { Previews Timespan=All years }\end{array}$ \\
\hline \#2 & $\begin{array}{l}\text { TOPIC: (zinc or zn) } \\
\text { Indexes=BIOSIS Previews Timespan=All years }\end{array}$ \\
\hline \#3 & $\begin{array}{l}\# 2 \text { AND \#1 } \\
\text { Indexes=BIOSIS Previews Timespan=All years }\end{array}$ \\
\hline \#4 & $\begin{array}{l}\text { TOPIC: }\left(\text { random}^{\star} \text { or placebo* or crossover* or "cross over" or allocat* or }\right. \\
\left(\left(\text { singl }{ }^{\star} \text { or doubl*) NEAR/1 blind*)) OR TITLE: (trial) }\right.\right. \\
\text { Indexes=BIOSIS Previews Timespan=All years }\end{array}$ \\
\hline
\end{tabular}


WHAT'S NEW

\begin{tabular}{lll}
\hline Date & Event & Description \\
\hline 3 February 2017 & $\begin{array}{l}\text { New citation required but conclusions } \\
\text { have not changed }\end{array}$ & Our conclusions remain unchanged. \\
\hline 3 February 2017 & New search has been performed & We did not identify any new trials for inclusion. \\
\hline
\end{tabular}

\section{CONTRIBUTIONS OF AUTHORS}

Ajibola Awotiwon wrote the protocol, with insightful comments from Olabisi Oduwole, Anju Sinha, and Charles Okwundu. Ajibola Awotiwon and Olabisi Oduwole reviewed the search outputs, selected studies for inclusion, and located copies of relevant studies. Ajibola Awotiwon and Anju Sinha extracted data.

Ajibola Awotiwon wrote the review under the supervision of Charles Okwundu.

Ajibola Awotiwon, Olabisi Oduwole, and Anju Sinha reviewed the updated search results.

Ajibola Awotiwon updated the review.

\section{DECLARATIONS OF INTEREST}

Ajibola Awotiwon: none known.

Olabisi Oduwole: none known.

Anju Sinha: none known.

Charles Okwundu: none known.

\section{SOURCES OF SUPPORT}

\section{Internal sources}

- Center for Evidence-based Health Care, Stellenbosch University, South Africa.

\section{External sources}

- No sources of support supplied

\section{N DEX TERMS}

\section{Medical Subject Headings (MeSH)}

Fever [therapy]; Measles [complications] [mortality] [^therapy]; Pneumonia [therapy]; Randomized Controlled Trials as Topic; Zinc [*administration \& dosage] [deficiency]

\section{MeSH check words}

Child; Humans 